\title{
ANALYSIS OF VARIABLES ASSOCIATED WITH PROMOTION OF RESISTANCE AND ITS ABROGATION IN T CELL-RECONSTITUTED NUDE MICE INFECTED WITH LEISHMANIA MAJOR
}

\author{
Heidrun Moll* and Graham F. Mitchell \\ The Walter and Eliza Hall Institute of Medical Research, Melbourne, Victoria 3050, Australia
}

\begin{abstract}
Upon intradermal challenge with the protozoan parasite Leishmania major, some mouse strains develop chronic cutaneous lesions, whereas other mouse strains show a resolving pattern of disease. The importance of $T$ cell-dependent immunity in resistance to cutaneous leishmaniasis is substantiated by the susceptibility to infection of athymic nude mice of both resistant and susceptible strains. Small numbers of $T$ lymphocytes from uninfected euthymic mice promote resistance in nude mice but $\mathrm{T}$ cells from chronically infected mice can impair this protective effect. In the present study we used an adoptive transfer system in which nude mice were reconstituted with $\mathrm{T}$ cells from normal or chronically infected mice in order to further investigate protection against disease or disease promotion. The results supported the following conclusions: (a) the hostprotective activity of $T$ cells from uninfected mice is highly effective even in long-term chronically infected nude mice, (b) T cell-mediated exacerbation of cutaneous disease does not involve enhancement of lesion development and is thus unlikely to be based on an accelerated proliferation of parasites in the lesion, (c) disease-promoting cells are not only found in genetically susceptible mice but can also be induced in genetically resistant mice, and (d) lymphoid organs of genetically susceptible mice chronically infected with $L$. major contain resistancepromoting cells in addition to disease-promoting cells. The data, together with those of others, continue to support the notion that recruitment with expansion and/or activation of different $T$ cell subsets underlies genetically based resistance and susceptibility of mice to $L$. major.
\end{abstract}

In a murine model of cutaneous leishmaniasis, reconstituted athymic nude mice have been used to establish that $\mathrm{L} 3 \mathrm{~T} 4^{+} \mathrm{T}$ cells are involved in promotion of resistance and promotion of disease (Mitchell et al., 1987; Moll et al., 1988). In this disease (Old World or zoonotic cutaneous leishmaniasis), infection is initiated by promastigotes of Leishmania major that invade macrophages, inside which they transform to amastigotes and multiply. The bulk of evidence indicates that the infected macrophage is the target of aggressive immune attack in resistant individuals (Louis and Milon, 1987).

Euthymic mice of BALB/c genotype differ from $\mathrm{CBA} / \mathrm{H}$ and $\mathrm{C} 57 \mathrm{BL} / 6$ mice in being nonhealers after cutaneous injection of $L$. major promastigotes. In our laboratory, using the $L$. major parasite line V121, both CBA/H and C57BL/6 mice are resistant to infection and usually develop only small lesions that heal rapidly within 1-2 mo. Cell transfer experiments have shown small numbers of lymphoid cells from syngeneic euthymic mice $\left(10^{5}-10^{6}\right)$ to be sufficient for establishing total resistance to $L$. major infection in

Received 15 December 1987; revised 12 May 1988; accepted 5 August 1988.

* Present address: Institut für Klinische Mikrobiologie, Universität Erlangen, 8520 Erlangen, West Germany. otherwise susceptible nude mice of $\mathrm{BALB} / \mathrm{c}$, $\mathrm{CBA} / \mathrm{H}$, and C57BL/ 6 genotypes (Mitchell et al., 1980). Compatibility at the I-A locus of the MHC is probably necessary for reconstitutive activities of T lymphocytes (Mitchell, 1983). T cells from chronically infected BALB/c mice can abrogate the protective effect of $T$ cells from uninfected mice in BALB/c nude recipients and thus exhibit disease-promoting activity (Mitchell et al., 1981). There is a close similarity between results obtained in the reconstituted nude mouse and the reconstituted sublethally irradiated mouse model used by the Wellcome group (Howard et al., 1980; Howard, 1986; Liew, 1986). Moreover, injection of anti-L3T4 antibodies promotes resistance in BALB/c mice (Titus et al., 1985; Sadick et al., 1987), a situation reminiscent of the minimally reconstituted $\mathrm{BALB} / \mathrm{c}$ nude mouse in that only small numbers of $\mathrm{L} 3 \mathrm{~T}^{+}$cells lead to resistance. Most of the data are compatible with the notion that resistance-promoting $T$ cells are of high frequency in uninfected euthymic mice relative to disease-promoting $T$ cells but that this ratio is changed in the lymphoid organs of chronically infected $\mathrm{BALB} / \mathrm{c}$ mice. The 2 functionally different $\mathrm{T}$ cell types have the same $\mathrm{L}_{3} \mathrm{~T}^{+}{ }^{+} \mathrm{Ly}-2^{-}$ phenotype and to date cannot be distinguished on the basis of expression of additional surface markers. They may therefore not belong to separate lineages but may rather differ in antigen 
specificity because a glycolipid of $L$. major can promote resistance and a carbohydrate derivative of this antigen can promote disease (Handman and Mitchell, 1985, 1987; Mitchell and Handman, 1986). Recent data from Locksley et al. (1987) strongly suggest that induction of $\mathrm{T}$ helper cells of type 1 relative to $T$ helper cells of type 2 (see Mosmann and Coffman, 1987) may underly resistance and susceptibility in mouse strains. The possibility exists that disease-promoting and resistance-promoting $\mathrm{T}$ cells have different specificities and produce different mediators.

The mode of action of disease-promoting $T$ cells remains poorly defined. It is generally believed that resistance-promoting $\mathrm{L} 3 \mathrm{~T}^{+}{ }^{+} \mathrm{T}$ cells operate by elaboration of lymphokines including interferon- $\gamma$ (Nacy et al., 1983; Titus et al., 1984), or through cell-cell contact (Sypek and Wyler, 1985), to promote activation of the infected macrophage with attendant destruction of the intracellular amastigotes. In the absence of definitive information on how $\mathrm{T}$ cells promote lesion persistence, we have continued to explore variables in the basic reconstituted nude mouse system in the expectation that more data will either enhance or reduce the validity of several current hypotheses (Louis and Milon, 1987).

\section{MATERIALS AND METHODS}

\section{Mice}

Female mice of the inbred strains BALB/c, C57BL/6, and $\mathrm{CBA} / \mathrm{H}$ were used at an age of $7-12 \mathrm{wk}$. Female athymic BALB/c nu/nu, C57BL/6 nu/nu, and CBA/H nu/nu (nude) mice were 6-8 wk of age at the commencement of experiments. All mice were bred under specific pathogen-free conditions at the Hall Institute but, during experimentation, were maintained under conventional conditions in a small isolation facility.

\section{Parasites and assessment of lesions}

The cloned virulent $L$. major parasite line V121 was produced from the human isolate LRC-L137 (Handman et al., 1983) and maintained by passage in BALB/c mice. Promastigotes were grown in vitro in blood/agar cultures (Handman et al., 1979). Stationary-phase promastigotes were washed and were injected in a volume of $50 \mu \mathrm{l}$ intradermally on the dorsum of the mouse close to the base of the tail. Lesion scores were determined at regular intervals according to the following system: $0=$ no lesion or healed scar; $1=$ small swelling (up to $5 \mathrm{~mm}$ in average diameter); 2 = large swelling (more than $5 \mathrm{~mm}$ in average diameter) or open lesion of less than $5 \mathrm{~mm}$ in average diameter; $3=$ open lesion of $5-10 \mathrm{~mm}$ in diameter; $4=$ open lesion greater than $10 \mathrm{~mm}$ in diameter and/or obvious metastases. Data are expressed as the arithmetic mean of the lesion scores for the groups of 4-6 mice and the number of mice with lesions relative to the total number of mice per group is given for several time points.

\section{Preparation of cell suspensions}

Single cell suspensions were prepared either from normal mouse spleens or from spleens or lymph nodes of mice that had been infected with $L$. major parasites. Cells from chronically infected BALB/c mice were obtained 70-100 days after parasite challenge when the donor mice had lesion scores of 3 and 4 , cells from infected C57BL/6 mice were obtained either from currently diseased donors with an unusually high lesion score of 3 or from recovered donors with healed lesions at 68 days of infection. Unseparated or nylon woolpurified T cells (Julius et al., 1973) were injected intraperitoneally in a volume of $0.2 \mathrm{ml}$ and the cell numbers used are given in the legends for individual experiments.

\section{RESULTS}

\section{Will disease-promoting cells enhance parasite proliferation and rate of lesion development?}

$T$ cells from chronically infected mice can impair the host-protective effect of $T$ cells from normal mice and restore permissiveness to $L$. major infection in nude mouse recipients (Mitchell et al., 1981). One possibility to account for this disease-promoting activity of $\mathrm{T}$ lymphocytes is that such cells, by unknown mechanisms, promote proliferation of amastigotes, which combined with recruitment of macrophages with inefficient killing capacity (Mirkovich et al., 1986) enhance the spread of the lesion. In order to test this possibility, BALB/c nude mice were injected with $2 \times 10^{7}$ nylon wool-purified $\mathrm{T}$ cells from chronically infected BALB/c mice and were challenged with either $10^{2}, 10^{4}$, or $10^{6} \mathrm{~L}$. major promastigotes, $10^{6}$ being the usual number of parasites used for challenge in this laboratory. Control groups of mice were infected with the same numbers of parasites but did not receive any lymphocyte inoculum. It can be seen in Figure 1 that the rate of lesion development is dependent on the number of parasites used for infection and is not increased by injection of $T$ cells. Upon infection with low numbers of promastigotes $\left(10^{2}\right.$ or $\left.10^{4}\right)$, the presence of $T$ cells with disease-promoting capacity does not give rise to early appearance and rapid expansion of lesions.

\section{Can resistance-promoting cells induce recovery of chronically infected nude mice?}

$T$ lymphocytes from uninfected euthymic mice have the capacity to induce resistance to cutaneous disease in nude mice when administered concomitantly with the parasite challenge. It is 


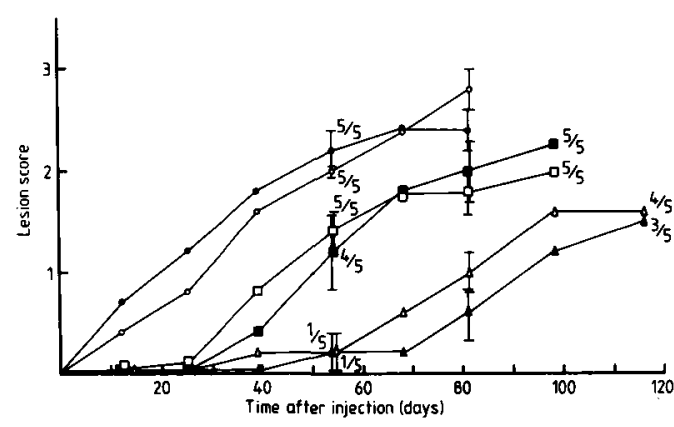

FIGURE 1. Effect of $T$ cells from chronically infected mice on the course of lesion development. On day $0,5 \mathrm{BALB} / \mathrm{c}$ nude mice per group were injected intradermally with $10^{2}(\triangle, \Delta), 10^{4}(\square, \square)$, or $10^{6}(O, \theta)$ promastigotes of $L$. major alone (open symbols) or in addition to $2 \times 10^{7} \mathrm{~T}$ cells from $\mathrm{BALB} / \mathrm{c}$ mice chronically infected with $L$. major (closed symbols) that were given intraperitoneally. As in succeeding figures, arithmetic means of the cutaneous lesion scores are indicated and the number of mice with lesions relative to the total number of mice per group as well as standard errors are given for certain time points.

conceivable that disease in nude mice may progress to the point that the injection of a limited number of $\mathrm{T}$ cells is unable to reverse the course of disease and to induce recovery. $\mathrm{CBA} / \mathrm{H}$ nude mice were therefore injected intradermally with $2 \times 10^{6}$ L. major promastigotes and individual groups were reconstituted on days $0,14,28,42$, and 56 with $2 \times 10^{7}$ nylon wool-purified $\mathrm{T}$ cells from euthymic $\mathrm{CBA} / \mathrm{H}$ mice. It can be seen in Figure $2 \mathrm{~A}$ that $\mathrm{T}$ cells are able to reverse the development of disease in $\mathrm{CBA} / \mathrm{H}$ nude recipients and induce complete healing of lesions when injected at any time during the course of infection. Even in $\mathrm{CBA} / \mathrm{H}$ nude mice with lesions greater than $5 \mathrm{~mm}$ in diameter, an injection of $T$ cells is fully protective. Similar results were obtained in an equivalent experiment using infected nude mice of BALB/c genotype (Fig. 2B). $B A L B / c$ nude mice that received syngeneic $T$ cells up to $\mathbf{4 2}$ days after challenge with $L$. major promastigotes were resistant to disease although lesions did not resolve completely in some of the recipients. Only when given at a very late stage of chronic disease ( 56 days after challenge with parasites) were $T$ cells unable to prevent the fatal effects of infection in this mouse strain. Thus, a firmly established infection, with large numbers of infected macrophages present, can be eliminated by an inoculum of $T$ cells both in genetically resistant and in genetically susceptible mouse strains.

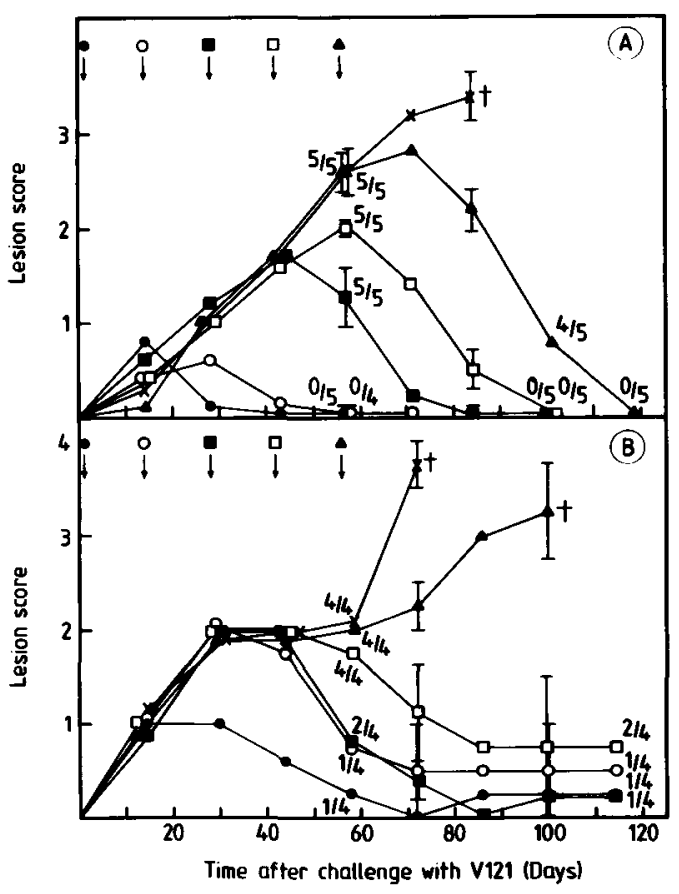

FIGURE 2. Reconstitution of infected nude mice with normal mouse $T$ cells at various time points. On day $0, \mathrm{CBA} / \mathrm{H}$ nude mice (A) or BALB/c nude mice (B) were injected intradermally with $2 \times 10^{6}$ promastigotes of $L$. major. Individual groups of 4 or 5 nude mouse recipients were injected intraperitoneally with $2 \times 10^{7}$ syngeneic $\mathrm{T}$ cells from uninfected euthymic mice on days $0(\bullet), 14(0), 28(\square), 42(\square)$, and $56(\Delta)$ or were not given any lymphocytes $(X)$. The cross symbols $(+)$ indicate deaths caused by metastases and visceralization of disease.

\section{Are resistance-promoting cells present in chronically infected mice?}

We have reexamined the question of whether the presence of resistance-promoting cells can be uncovered in a population of lymphoid cells from chronically infected BALB/c mice (Liew et al., 1982; Mitchell, 1983) using a cell titration approach. Upon challenge of BALB/c nude mice with $10^{6} \mathrm{~L}$. major promastigotes and reconstitution with numbers of cells ranging from $10^{2}$ to $10^{6}$ and $10^{5}$ to $10^{8}$ in 2 different experiments, it was found that resistance-promoting cells can indeed be detected in chronically infected BALB/c mice (Fig. 3). Nude mice given $10^{4}$ or $10^{5}$ cells in one experiment and $10^{5}$ cells in another were resistant to $L$. major infection, whereas recipients of less than $10^{4}$ or more than $10^{5}$ cells were susceptible. Thus, it is possible to titrate out disease-promoting cells and to uncover the activi- 


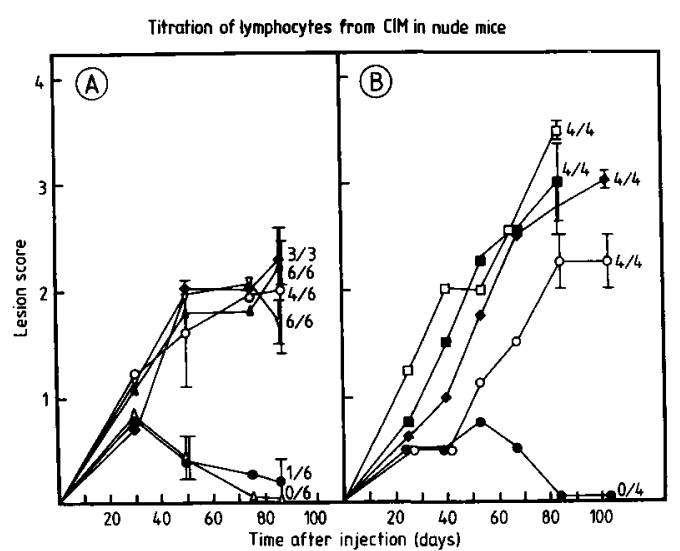

FIGURE 3. Titration of lymphocytes from chronically infected mice in nude mouse recipients. A. Groups of 3 or $6 \mathrm{BALB} / \mathrm{c}$ nude mice were injected with $10^{2}$ $(\nabla), 10^{3}(\Delta), 10^{4}(\triangle), 10^{5}(\Theta)$, or $10^{6}(O)$ pectoral and mesenteric lymph node cells from chronically infected $\mathrm{BALB} / \mathrm{c}$ mice and were challenged with $10^{6} \mathrm{~L}$. major promastigotes on days 1 and 14. B. Groups of $4 \mathrm{BALB} / \mathrm{C}$ nude mice were injected with $10^{5}(0), 10^{6}(O), 10^{7}(\square)$, or $10^{8}(\square)$ lymph node and spleen cells from chronically infected BALB/c mice and were challenged with $10^{6}$ L. major promastigotes on day 0 . Control groups were not given any lymphocytes $(\boldsymbol{})$.

ties of resistance-promoting cells in chronically infected mice.

\section{Are disease-promoting cells present in infected genetically resistant mice?}

We have previously demonstrated that the disease-promoting activity of cells from genetically susceptible BALB/c mice can be increased by injection of a carbohydrate derivative of a hostprotective L. major glycolipid antigen (Mitchell and Handman, 1986). Among genetically resistant mice, C57BL/6 can become more susceptible to chronic disease provided large amounts of this carbohydrate are injected in Freund's adjuvant. We have therefore examined whether lymphocytes taken from currently infected C57BL/6 mice are less able to promote resistance to infection in syngeneic nude mouse recipients. For this experiment, 2 C57BL/6 mice with lesion scores of 3 and with no sign of healing were chosen as spleen cell donors. These lesions were much larger than those usually seen in euthymic C57BL/6 mice challenged with $L$. major because mice of this strain generally develop only small lesions of score 1 to 2 that heal within 1-2 mo. For comparison, C57BL/ 6 mice that represented the standard course of infection and had recovered from infection were used and either $3 \times 10^{6}$ or

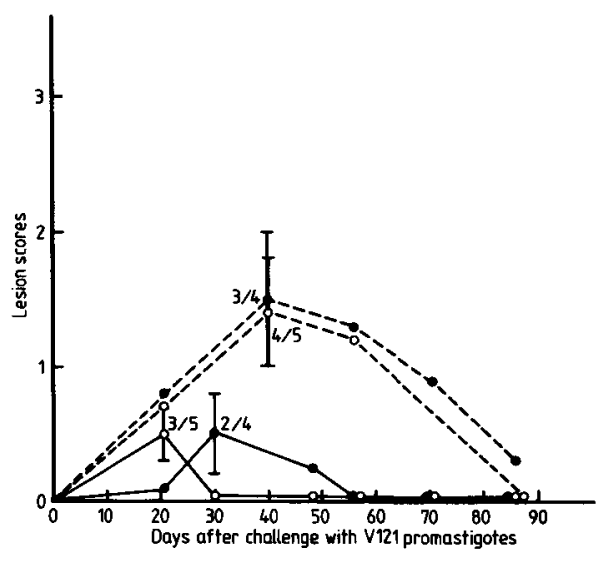

FIGURE 4. Reconstitution of nude mice with $T$ cells from infected genetically resistant mice. On day 0 , C57BL/ 6 nude mice ( 4 or 5 per group) were injected intradermally with $10^{6}$ promastigotes of $L$. major and intraperitoneally with either $3 \times 10^{6}(\mathrm{O})$ or $3 \times 10^{7}$ (๑) spleen cells from euthymic C57BL/6 mice that had recovered from infection (solid lines) or were currently infected with $L$. major (broken lines).

$3 \times 10^{7}$ spleen cells from each donor type were injected to C57BL/6 nude mice that were challenged with $10^{6} \mathrm{~L}$. major promastigotes. Unless reconstituted with lymphocytes from syngeneic euthymic mice, C57BL/6 nude mice, like nude mice from other strains, are highly susceptible to disease and develop progressing lesions with fatal outcome. The course of lesion development in Figure 4 shows that lymphocytes from currently infected euthymic mice are less able to mediate resistance to infection in nude mice, because lesions are larger and take longer to heal than in nude mice that received cells from recovered euthymic mice.

\section{DISCUSSION}

The studies reported in this paper supplement 2 other approaches that are also designed to examine the basis of $\mathrm{T}$ cell-dependent disease resistance and disease promotion in murine cutaneous leishmaniasis. These other approaches are the subdivision of the $\mathrm{L} 3 \mathrm{~T} 4^{+} \mathrm{T}$ cell population according to additional surface markers including Ly-24 (Pgp-1) and the functional characterization of the resulting subsets (Moll and Scollay, submitted for publication) as well as the in vivo and in vitro analysis of $T$ cell responses to defined glycoconjugate antigens of $L$. major (Moll et al., submitted for publication).

The results of the experiments reported here substantiate a conclusion made from other ex- 
periments, namely that disease-promoting cells can be induced in genetically resistant C57BL/6 mice (Fig. 4). In addition, we extended the notion that lymphoid organs of genetically susceptible BALB/c mice contain a mixture of disease-promoting and resistance-promoting cells by demonstrating for the first time that even BALB/c mice chronically infected with $L$. major possess resistance-promoting cells. In these mice, disease-promoting cells can be titrated out to uncover the activities of resistance-promoting cells that are still present at a frequency apparently as high as in lymphoid organs of uninfected mice (Fig. 3). The alternative explanation is that the 2 cell types are one and the same, the outcome of infection depending in some way on the numbers of cells present. Against this interpretation is the earlier observation (Mitchell, 1983) that using lymphocytes from severely affected donor mice with late-stage visceralized disease, no cell dose was found to mediate resistance (see also Liew, 1986). Presumably, the balance between numbers of disease-promoting cells and resistance-promoting cells will depend on the duration (severity) of infection and the location from which cells are harvested in chronically infected mice. The proportion of activated $\mathrm{T}$ cells with disease-promoting activity appears to be highest in lymph nodes that are draining the site of the lesion (Moll and Mitchell, unpubl. obs.). From the recent study of Locksley et al. (1987), analyses of $T$ helper cells of type 1 and type 2 become critical to the understanding of disease outcome in all such experiments. However, no surface markers to distinguish these $\mathrm{L} 3 \mathrm{~T}^{+}{ }^{+} \mathrm{T}$ cell subsets are available as yet.

A new observation is that $\mathrm{T}$ cells from donor mice chronically infected with $L$. major do not enhance the rate of lesion development in nude recipients. Thus, in mice given low numbers of parasites, the presence of disease-promoting $T$ lymphocytes does not change the time point of first appearance of skin lesions (Fig. 1). Because during development of the primary infection in genetically susceptible mice, the increase in lesion size reflects the concomitant increase in the number of parasites in the lesions (Hill et al., 1983), it can be concluded that $T$ cell-dependent exacerbation of cutaneous disease is most unlikely to be due to accelerated proliferation of amastigotes in the lesion. Rather, the data are consistent with the hypothesis that $\mathrm{T}$ cells promote disease by inhibiting the activity of hostprotective T lymphocytes. Another new finding reported in this paper is that the host-protective activity of $T$ cells from uninfected donor mice is extraordinarily potent even in long-term chronically infected nude recipients (Fig. 2). In contrast to the results obtained after inoculation of $T$ cells to chronically infected nude mice, attempts to reverse disease in chronically infected euthymic mice using lymphocyte populations have been unsuccessful (Mitchell, 1983).

Some discussion on the cellular events in C57BL/6 mice infected with $L$. major is warranted. Using a crude in vivo limiting dilution assay in nude mice, we have not been able to show a marked increase in the apparent frequency of resistance-promoting cells in recovered hyperimmune mice relative to naive C57BL/6 mice (Mitchell et al., 1987). On the other hand, using the same type of in vivo assay, the apparent frequency of disease-promoting cells is increased in chronically infected $\mathrm{BALB} / \mathrm{c}$ mice and in BALB/c mice immunized with a carbohydrate antigen of $L$. major isolated by affinity chromatography with a monoclonal antibody (Mitchell and Handman, 1986; Mitchell et al., 1987). This same carbohydrate antigen, provided it is injected in high doses and in Freund's adjuvant (and then not in every experiment), can prolong subsequent disease in C57BL/6 mice. We speculate that most genetically resistant mice are nonresponders to this and other disease-promoting antigens but that they can be stimulated to respond under some conditions. In the experiment reported here (Fig. 4), cells from diseased C57BL/6 mice were less able to promote resistance in nude mice than cells from recovered C57BL/6 mice. It becomes important to determine whether, in a vaccination program, some humans are high responders to disease-promoting antigens (like BALB/c mice) and others, though relatively resistant, can respond to such antigens under some circumstances (like C57BL/6 mice).

\section{ACKNOWLEDGMENTS}

We thank Susan Wood and Mandy Ludford for technical assistance. This work was supported by the Australian National Health and Medical Research Council, the Rockefeller Foundation Great Neglected Diseases Network, the Leishmaniasis Component of the UNDP/World Bank/ WHO Special Programme for Research and Training in Tropical Diseases, and by Fellowship Mo418/1-1 from the Deutsche Forschungsgemeinschaft, West Germany. 


\section{LITERATURE CITED}

handman, E., R. Ceredig, and G. F. Mitchell. 1979. Murine cutaneous leishmaniasis: Disease patterns in intact and nude mice of various genotypes and examination of some differences between normal and infected macrophages. Australian Journal of Experimental Biology and Medical Science 57: 929.

- , R. E. Hocking, G. F. Mitchell, AND T. W. SPITHILL. 1983. Isolation and characterization of infective and non-infective clones of Leishmania tropica. Molecular and Biochemical Parasitology 7: $111-126$.

- _, AND G. F. MITCHELL. 1985. Immunization with Leishmania receptor for macrophages protects mice against cutaneous leishmaniasis. Proceedings of the National Academy of Sciences USA 82: 5910-5914.

$\longrightarrow$, AND - 1987. Leishmania-macrophage interaction: Role of parasite molecules in infection and host protection. In Molecular strategies of parasitic invasion, UCLA Symposia on Molecular and Cellular Biology, New Series, Vol. 42, N. Agabian, H. Goodman, and N. Noguiera (eds.). Alan R. Liss Inc., New York, pp. 493-500.

Hill, J. O., R. J. North, AND F. M. Collins. 1983. Advantages of measuring changes in the number of viable parasites in murine models of experimental cutaneous leishmaniasis. Infection and Immunity 39: 1087-1094.

HowARD, J. G. 1986. Immunological regulation and control of experimental leishmaniasis. International Review of Experimental Pathology 28: 79116.

-, C. Hale, AND F. Y. LIEw. 1980. Immunological regulation of experimental cutaneous leishmaniasis. III. Nature and significance of specific suppression of cell-mediated immunity in mice highly susceptible to Leishmania tropica. Journal of Experimental Medicine 152: 594-607.

Julius, M. H., E. Simpson, AND L. A. Herzenberg. 1973. A rapid method for the isolation of functional thymus-derived murine lymphocytes. European Journal of Immunology 3: 645-649.

Liew, F. Y. 1986. Cell-mediated immunity in experimental cutaneous leishmaniasis. Parasitology Today 2: 264-270.

- C. Hale, AND J. G. Howard. 1982. Immunological regulation of experimental cutaneous leishmaniasis. V. Characterization of effector and specific suppressor 'T cells. Journal of Immunology 128: 1917-1922.

LoCKSLEy, R. M., F. P. HeInzel, M. D. SAdick, B. J. HoladAY, AND K. D. GardNER, JR. 1987. Murine cutaneous leishmaniasis: Susceptibility correlates with differential expansion of helper T-cell subsets. In Immunobiology of experimental leishmaniasis, J. A. Louis and G. Milon (eds.). Annales de l'Institut Pasteur/Immunology 138: 744-749.

Louis, J. A., AND G. MiLON (eds.). 1987. Immunobiology of experimental leishmaniasis. Annales de l'Institut Pasteur/Immunology 138: 737-795.

Mirkovich, A. M., A. Galelli, A. C. Allison, AND F. Z. MODABBER. 1986. Increased myelopoiesis during Leishmania major infection in mice: Generation of 'safe targets', a possible way to evade the effector immune mechanism. Clinical and Experimental Immunology 64: 1-7.

Mitchell, G. F. 1983. Murine cutaneous leishmaniasis: Resistance in reconstituted nude mice and several $\mathrm{F}_{1}$ hybrids infected with Leishmania tropica major. Journal of Immunogenetics 10: 395412.

, J. M. Curtis, E. Handman, and I. F. C. MCKENZIE. 1980. Cutaneous leishmaniasis in mice: Disease patterns in reconstituted nude mice of several genotypes infected with Leishmania tropica. Australian Journal of Experimental Biology and Medical Science 58: 521-532.

, R. G. Scollay, and E. HANDMAN.

1981. Resistance and abrogation of resistance to cutaneous leishmaniasis in reconstituted BALB/c nude mice. Australian Journal of Experimental Biology and Medical Science 59: 539-554.

$\longrightarrow$, AND E. HANDMAN. 1986. The glycoconjugate derived from a Leishmania major receptor for macrophages is a suppressogenic, disease-promoting antigen in murine cutaneous leishmaniasis. Parasite Immunology 8: 255-263.

- H. Moll, M. J. McConville, T. W. Spithill, G. Z. Kidane, N. Samaras, and M. J. ELHAY. 1987. Resistance and susceptibility of mice to Leishmania major: A view from Melbourne. In The immunobiology of experimental leishmaniasis, J. A. Louis and G. Milon (eds.). Annales de 1'Institut Pasteur/Immunology 138: 738-743.

Moll, H., R. Scollay, and G. F. Mitchell. 1988. Resistance to cutaneous leishmaniasis in nude mice injected with $\mathrm{L} 3 \mathrm{~T}^{+}{ }^{+} \mathrm{T}$ cells but not with $\mathrm{Ly}-2^{+} \mathrm{T}$ cells. Immunology and Cell Biology 66: 57-63.

Mosmann, T. R., AND R. L. CoffMAN. 1987. Two types of mouse helper $\mathrm{T}$-cell clone. Immunology Today 8: 223-227.

NACY, C. A., S. L. James, W. R. BENJAMIN, J. J. FARRAR, W. T. HOCKMEYER, AND M. S. MELTZER. 1983. Activation of macrophages for microbicidal and tumoricidal activities by soluble factors from EL4 , a continuous $T$ cell line. Infection and Immunity 40: $820-824$

Sadick, M. D., F. P. Heinzel, V. M. Shigekane, W. L. FISHER, AND R. M. LoCKSLEY. 1987. Cellular and humoral immunity to Leishmania major in genetically susceptible mice after in vivo depletion of L3T4 ${ }^{+} \mathrm{T}$ cells. Journal of Immunology 139: 1303-1309.

SYPEK, J. P., AND D. J. WYLER. 1985. Cell contactmediated macrophage activation for antileishmanial defense: Mapping of the genetic restriction to the I region of the MHC. Clinical and Experimental Immunology 62: 449-457.

Titus, R. G., R. Ceredig, J.-C. Cerottini, and J. A. LouIs. 1985. Therapeutic effect of anti-L3T4 monoclonal antibody GK1.5 on cutaneous leishmaniasis in genetically-susceptible BALB/c mice. Journal of Immunology 135: 2108-2114. , A. Kelso, AND J. A. Louis. 1984. Intracellular destruction of Leishmania tropica by macrophages activated with macrophage activating factor/interferon. Clinical and Experimental Immunology 55: 157-165. 